\title{
Unilateral multiple thoracic hydatid cysts: a rare presentation
}

\section{El Hassane Kabiri' ${ }^{1}$ (D) Massine El Hammoumi ${ }^{1,2}$, Meryem Kabiri ${ }^{2}$}

'Department of Thoracic Surgery, Mohammed V Military Teaching Hospital, Rabat, Morocco

${ }^{2}$ Faculté de Médecine et de Pharmacie, Mohammed V University, Rabat, Morocco

Hydatidosis, when present in multiple thoracic locations, requires a synchronous or successive approach, which can lead to an increased risk of complications.

A 50-year-old female with a history of hepatic hydatid cyst surgery 30 years ago presented with chest pain and dyspnea. Chest X-ray revealed multiple homogeneous opacities of the right hemithorax (Figure 1A). Thoracic and abdominal computed tomography (CT) scans (Figure 1B, 1C, and 1D) showed multiple hydatid cysts in the right hemithorax [2, 3]. Hydatidosis serology (ELISA) was positive. After 2 weeks of preoperative Albendazole treatment, the patient underwent a posterolateral thoracotomy. Protection of the surgical field was maintained with packs immersed by a scolicidal solution and difficult pneumolysis. All the cysts were treated via cystectomies or pericystomies with capitonnage. There was no trans-diaphragmatic fistulation. The diagnosis was confirmed by pathological examination. The patient was discharged uneventfully on the $7^{\text {th }}$ postoperative day. No further complications or recurrence occurred during 12 months of follow-up.
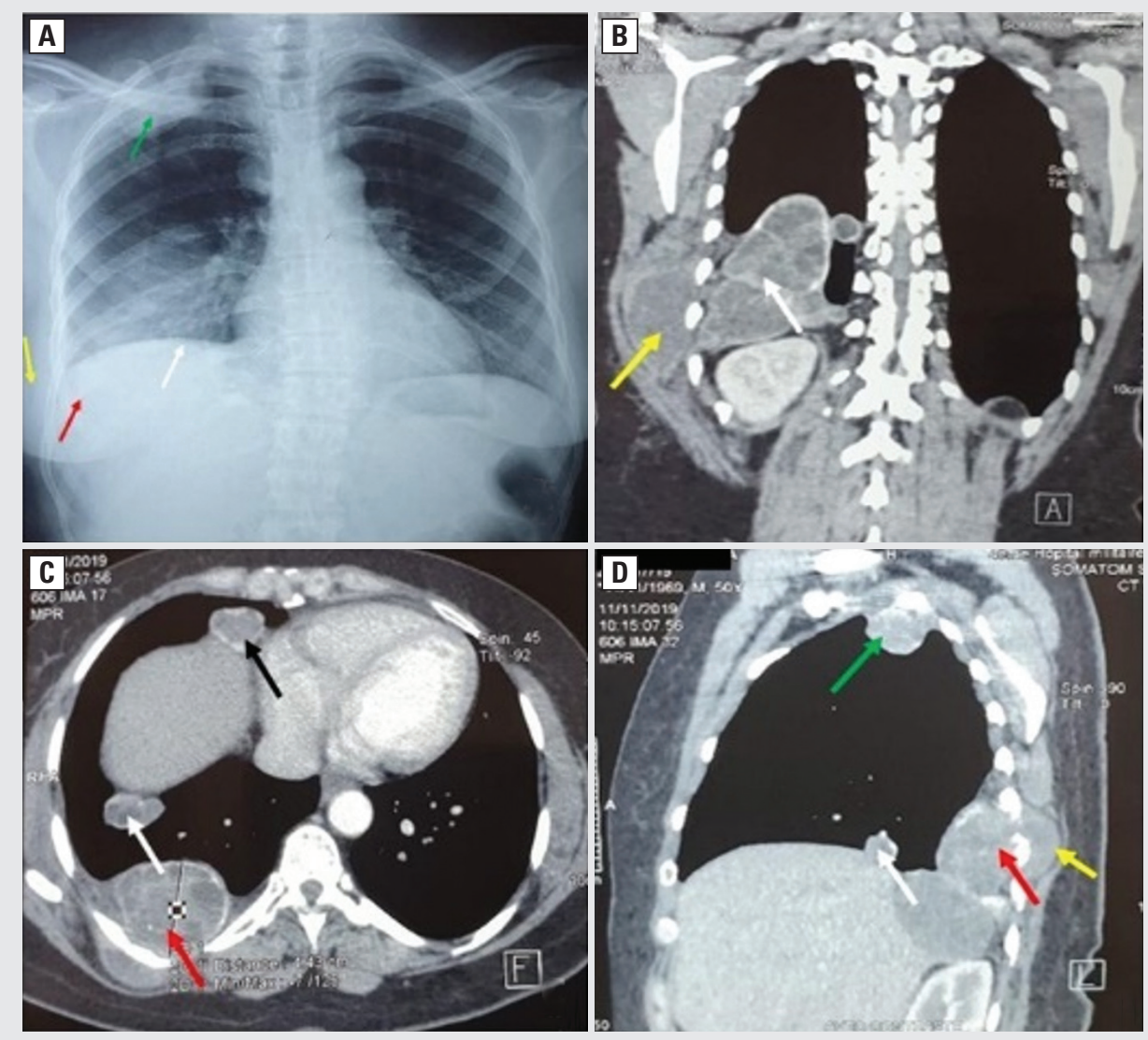

Figure 1. A. Chest x-ray showing multiple right thoracic opacities; B-D. Chest computed tomography showing multiple right thoracic hydatid cysts: chest wall (yellow arrow), diaphragmatic (white arrow), pericardial (black arrow), pleural (red arrow), and pulmonary (green arrow) regions

Address for correspondence: El Hassane Kabiri, Head of Department of Thoracic Surgery, Mohammed V Military Teaching Hospital, Hay Riad 10100, Rabat, Morocco, e-mail: hassankabiri@yahoo.com

Conflict of interest: None declared

DOI: 10.5603/ARM.a2021.0096 | Received: 10.03.2021 | Copyright (C 2021 PTChP | ISSN 2451-4934 | e-ISSN 2543-6031

This article is available in open access under Creative Common Attribution-Non-Commercial-No Derivatives 4.0 International (CC BY-NC-ND 4.0) license, allowing to download articles and share them with others as long as they credit the authors and the publisher, but without permission to change them in any way or use them commercially. 
Multiple thoracic hydatid disease is usually secondary to dissemination after spontaneous or preoperative rupture of the hepatic cyst into the thorax. Therefore, the right hemithorax is the most affected region [1,2].

In terms of thoracic spread, the diaphragm is the first location affected. This occurs most often secondary to intraoperative contamination of the hepatic location due to precautions taken during surgery. This complication is usually asymptomatic, although symptoms can occur in complicated forms such as rupture or infection of the cyst or by compression of the neighboring organs. Imaging with CT gives important diagnostic information about the cysts (location, size, character, and relationship to surrounding vital structures) [2-4]. The treatment is based on successive or simultaneous surgery via excision of hydatid cysts. Preoperative medical treatment with albendazole is recommended by some authors because it sterilizes the contents of the cyst and prevents postoperative spread. Strict precautions and careful handling of the cyst are essential during surgery. Therefore, the operating field must be absolutely protected with scolicidal solutions such as hypertonic saline, povidone iodine, or hydrogen peroxide in all cases [1,4]. Conservative treatment options such as cystotomy and pericystectomy with capitonnage of the residual cavities are the most effective procedures $[3,5]$, whereas radical surgery (lobectomy or more) is rarely indicated. The recurrence rate is reported to be higher with conservative surgery rather than radical surgery [4] due to failure to totally remove the smallest cysts and/or prevent spread during surgery. The follow-up after surgery must be extended to detect any recurrence or dissemination; this is especially true is for endemic areas of hydatidosis [2].

We concluded that a CT scan gives important diagnostic information and aids in therapeutic management of the cysts. The treatment is based on surgical conservative procedures associated with medical therapy.

\section{References:}

1. Kabiri EH, El Maslout A, Benosman A. Thoracic rupture of hepatic hydatidosis (123 cases). Ann Thorac Surg. 2001; 72(6): 18831886, doi: 10.1016/s0003-4975(01)03204-0, indexed in Pubmed: 11789764.

2. Kermenli T, Yalçınöz K, Polat ME. Intrathoracic multiple recurrence and bilateral endobronchial rupture of cyst hydatid disease; the rare cause of anaphylaxis. Respir Med Case Rep. 2017; 21: 113-115, doi: 10.1016/j.rmcr.2017.04.002, indexed in Pubmed: 28458996.

3. Singh J, Rana SS, Singh H, et al. Multiple intrathoracic hydatids. Asian Cardiovasc Thorac Ann. 2010; 18(1): 88-89, doi: 10.1177/0218492309355197, indexed in Pubmed: 20124306.

4. Saeedan MB, Aljohani IM, Alghofaily KA, et al. Thoracic hydatid disease: a radiologic review of unusual cases. World J Clin Cases. 2020; 8(7): 1203-1212, doi: 10.12998/wjcc.v8.i7.1203, indexed in Pubmed: 32337194.

5. Kabiri ElH, Traibi A, El Hammoumi M, et al. Parenchyma sparing procedures is possible for most pulmonary hydatid disease without recurrence and low complications. Med Arch. 2012; 66(5): 332-335, doi: 10.5455/medarh.2012.66.332-335, indexed in Pubmed: 23097973. 